29th. - Was requested to see the child to-day for an erup. tion which was first observed on the $27 \mathrm{th}$. 'The child is very cross and restless, aud has a slight cough. There are two brown scabs on the arm where the vaccination was performed, and no unusual appearance around them. The skin of the face, trunk, arms, and legs is covered in some places with oval disks. of the size of and resembling a vaccine vesicle; it is slightly raised above the surrounding skin, but with a flat surface and marked thus: a red outer margin; an inner circle of a white pellucid appearance and a little broader than the outer circle, and a central oval area; red, and not depressed. After reaching this stage they do not proceed further, but gradually disappear. At other parts several of these have coalesced, forming a large area, irregular in outline, very much resembling the large white patches sometimes seen in urticaria, but without the surrounding redness. The surface has a slight blush diffused over it, with a white translucency intermixed, and small accuminated vesicles scattered thickly over it. Ordered, a saline mixture, with a little ipecacuanha wine for cough.

31st. - Eruption out very vivid last night, but it has receded this morning.

Feb. 2nd.-Child much better; patches have almost disappeared, leaving the cuticle in some places shrivelled up, in others no trace of the disease, except a slight discoloration, and in one place on the chest a dry brown scab. A patch near the navel is still covered with vesicles.

April 9th. - A few scars here and there over the trunk.

ON

\section{THE ADMINISTRATION OF NUX VOMICA.}

\section{BY J. HAMERTON GREENWOOD, ESQ., L.S.A., Manchester.}

\section{To the Editor of THE LANCET.}

SrR,-The committal of Palmer, and the interest excited in all minds regarding the effects of strychnine, reminding me of a case which occurred some years ago when holding a public appointment, I beg to forward it to you. It was written out at the time by a colleague, who had charge of the case. He is since dead, or it would have appeared long ago in your columns. For the correctness of symptorns, post-mortem appearances, $\& c$, I can vouch, having seen the case throughout, and made the sectio cadaveris myself. Hoping it will be of sufficient importance to trouble you with,

I remain, Sir, your obedient servant,

\section{J. Hamerton Grenwood.}

M. J. G- aged thirty, a florid, healthy-looking woman, came under treatment June 17th, 185-, complaining of pain and tenderness in the region of the spine, with inability to move her lower extremities with facility. These symptoms were probably hysterical, and the whole appearance of the case,-her very countenance indicated it,-her capriciousness of temper and appetite, together with a deep religious feeling, all tended to confirm such a diagnosis. She had, however, never suffered distinct hysterical paroxysms, although, as usual, the menstrual function was irregular, but not arrested. The case, indeed, simulated spinal disease, so the poor creature's back became for four months the seat of severe counter-irrita tion-croton oil liniment, potassa fusa, the actual cautery, \&c. She was able to wall about, and went to the closet regularly without assistance. So far had she improved, when on the 7 th of October the following was prescribed:-Nux vomica powder three grains; saccharized carbonate of iron, ten grains; made into powders, to be taken three times a day.

With the exception of some slight increase of appetite, the remedy produced no obvious effect till a fortnight had elapsed, at the end of which time slight diarrhoa set in, with colicky pains. A dose of chalk mixture was ordered, and the purging continuing, the nux vomica was stopped on the 23rd. She then began to have a little bilious vomiting, but these symptoms subsided under the use of chalk, opium, effervescing salines, and mustard plaster, S.C. On the 28th, she began to complain of tinnitus aurium, drowsiness, increased sensi bility to light and sound, formication, numbness of the head and upper extremities; she expressed some fears of losing her 654 speech, which had become impaired. Ordered, oxide of silver, two grains; saline mixture, one ounce, in a state of effervescence, every three hours: mustard plaster, S.C.

On the 31st she became delirious; excessive thirst and strange sensations about the head. The next morning, Nov. 1st, she was able to articulate a few words only, which were her last. Tetanic symptoms now became manifest, which affected the muscles of the face and upper extremities, the fingers and arms being drawn forcibly by clonic muscular contractions. In the course of the day decided trismus set in; during the slight intervals of relaxation, deglutition was very imperfectly performed; the pupil was somewhat dilated, sluggish, but never insensible to light. It was evident the poor creature's intellect. was unimpaired; she was conscious of all around her, made various efforts to speak, swallow, protrude her tongue, but in vain. Brandy, wine, ammonia, and beef-tea wero given as long as she could swallow, and then nutrient enemata, with occasional turpentine ones, were administered. The pulse was. weak, small, and frequent; the skin throughout very hot, and a peculiar erythematous eruption about the neck, arms, and shoulders. She turned her head constantly to the left side, and her eyes were fixed in the same direction. Catheterism was performed twice.

During the next day, Nov. 2nd, the spasms increased. The left angle of the mouth was drawn upwards, like a sardonic smile; the lower extremities were unaffected throughout, nop had the patient any precursory twitchings, which are usually observed in paraplegia treated with strychnine. In fact, the whole force of the poison seemed concentrated in the system, manifesting itself, firstly by gastric and intestinal irritation, and then suddenly affected the cerebro-spinal system. On.the 3rd of November the sphincters become relaxed, motions passing involuntarily, and catheterism had to be again performed. This continued up to the time of her death. She remained in this state up to the 4 th ; the respiration then began to be affected, and in the evening she was seized with a strong tetanic convulsion, which continued several minutes. Respiration ceased; the face became livid; brows contracted; lips drawn wide apart, showing the gums and clenched teeth; hissing of the saliva through them. The face was horribly distorted; the heart still beat feebly. During the night she had four similar paroxysms-respiration laborious, skin very hot. She sank towards morning, and at five A.M. death closed the scere. Death appeared to be due partly to the want of nourish. ment and the exhausted powers of the heart, and partly to the impeded action of the respiratory muscles, although she did not actually die during one of these fits : it was a continuation of aphnoe with asthenia.

Autopsy, thirty hours after death.-Features placid; venous turgescence, on separating the calvarium; brain firm and paler than natural-no softening of it or spinal cord, but membranes of the latter congested; heart contracted and empty; lungs healthy; recent slight inflammatory appearance of ileum, near ileo-cecal valve. Excepting this, no appearance of disease. Uterus healthy; ovaries pale, but healthy. No indication of organic disease in any part of the body; spine (bones) not diseased.

From the details of the foregoing case, we may come to the conclusions-

lst. - That nux vomica is a drug acting more powerfully in certain constitutions.

2nd.-That it is cumulative in its action.

3rd.--That it affects the encephalon as well as the medulla spinalis.

Three grains three times a day are perhaps above the ordinary average, yet Royle says nux vomica may be given in doses of five to fifteen grains. This patient only took altogether seven scruples in sixteen days, which, according to Dr. Taylor, is only equal to three-quarters of a grain of the alkaloid strychnine. Idiosyncrasy has doubtless much influence, or how are we to compare this case with others, in which one grain and a half, and even three grains, of strychnine, have been given for some time without injury. Pereira says that some individuals are more susceptible than others of its action; that as much as fifty grains have been given at once, yet tetanic symptoms have been produced by a dose of the alkaloid equal to only sixteen grains of the powder. Had this woman really suffered from paraplegia, she would doubtless have had twitchings of the lower extremities, and have borne a much larger dose of the medicine. Guy seems to allude to the cumulative effects of strychnia. In this case, the specific action of the poison on the nervous system was not manifested for five days after the medicine had been discontinued, and then its effects were almost suddenly produced as the effort of Nature to throw it 
off by the bowels was interfered with. This case would seem to caution us in administering nux vomica in any other than paralytic cases, and particularly as our authorities seem to differ so widely as to the dose and effects of this powerful remedy. Bayle employed nux vomica in hysteria and epilepsy; but, as Pereira observes, its use is certainly contraindicated in spasmodic or convulsive diseases, and indeed, in one of these cases, it caused paralysis and death. Christison says nux vomica may be given in small doses, frequently repeated, so as to imitate exactly the phenomena of tetanus from natural causes. Mr. Baynham states that he has often given one scruple three times a day, without any sensible effect. $\mathrm{He}$ adds, the drug must materially differ in strength, either in relation to the age of its growth, or the time it has been kept.

June, 1856 .

ON A CASE OF

\section{LACERATION OF THE PERIN AUM,}

WITH COMPLETE RUPTURE OF THE RECTO-VAGINAL SEPTUM AND SPEIINCTER ANI, AND CURE WITHOUT AN OPERATION.

By ARTHUR TAYLOR, M.R.C.S., L.S.A., \&c., Kingsclere.

As the following case is highly interesting, in a practical point of view, and tends to disprove the generally received notion that complete rupture of the perinæum and sphincter ani are incurable without an operation (which, by the bye, is not invariably successful), I forward the following outline to you for publication:-

On the 20 th of December, 1850, I was summoned to attend in her confinement Mrs. T__, the wife of an agricultural labourer. On making the usual examination, per vaginam, I discovered that the head did not present that conical form which is commonly the case when the presentation is natural, and a little further manipulation demonstrated the fact that the occiput was opposed to the sacrum. This, it will be remembered, is one of the most common causes of laceration; the pelvis was, however, exceedingly capacious, and I therefore had little doubt but that the labour, with common care, would be speedily brought to a favourable termination. After the lapse of about half an hour from the commencement of my visit, the head began to press upon the perineum, from which time, up to the occurrence of the accident, I was very careful to give the necessary support which the peculiarities of the case required. My patient was now lying in the usual position, on her left side, her knees well drawn up, and her feet firmly placed against the bed-post, awaiting the next pain, my hand at the same time resting against her perinæum. At this juncture, and in the most sudden and unexpected manner, while pressing her feet forcibly against the bed-post, she withdrew herself most completely out of my reach, and before I could again give such assistance as was necessary, the child was completely expelled. The act was almost instantaneous. I, of conrse, conceived what was the true state of affairs, and an examination too sadly verified my fears. At that time such cases were generally deemed incurable, and a poor creature so afflicted was considered only as an object of pity and disgust; it was, therefore, with much pain that I reflected on the seeming hopelessness of her condition. Having approximated the knees by a bandage, and informed my patient of what had occurred, I returned home without doing anything more. At my next visit, the following day, on introducing the forefinger of one hand into the rectum, and that of the other into the vagina, it was with some difficulty that I could reach the upper part of the lacerated septum, having done which, and placed the points of the two fingers together, I then withdrew them through the whole of the torn parts without any opposition. It will thus he seen that not only were the sphincter and perineum completely ruptured, but the recto-viginal septum also. In order to give the laceration a chance of healing, 1 determined to lock up the bowels, and with this intention administered repeated doses of the compound chalk mixture, with tincture of opium. On my third visit, it was gratifying to find that a small band of perinæum, just behind the commissure, had united, and that the septum had healed slightly from above downwards.

At my fourth visit, still greater improvement had taken place, and, in addition, the sphincter was beginning to heal. When I next saw her, on the fifth day, my visits having been diurnal, the case had in every respect greatly improved. On the sixth day, the septum was so nearly healed that not more than half an inch remained nnclosed. At the end of one week the edges of the sphincter and perinæum had become quite united, the latter being a little shorter than before the accident, while the septum was so nearly closed, that on passing a finger into the rectum, and another into the vagina, there was some difficulty in making the nails of such fingers touch through the wound.

Up to this period the bowels had been kept free from any evacuation; and as there was now some febrile symptoms setting in, a dose of castor oil was administered, and continued daily for another week. In a fortnight more my patient had perfectly recovered, and she has since borne children without any untoward event.

In the above treatment of the case it will be seen that little was attempted to be done; yet it clearly shows that Nature, slightly assisted by art, is sometimes able to effect a cure where it is least expected.

June, 1856.

\section{REPORT OF A CASE OF}

\section{WANT OF OSSEOUS DEVELOPMENT OF} THE CRANIUM AT BIRTH, \&c.

BY JOHN S. BEALE, EsQ., M.R.C.S.E., Harrow-road.

Mrs. H-, aged twenty-three, mother of one healthy child, was delivered, on the 30th of May, of a full-sized female child, exhibiting the following deviations from nature:-It had spina bifida, occupying the last two lumbar vertebræ, and part of the sacral region, about the size of the palm of the hand; the spinous processes and laminæe of the vertebre were deficient, likewise the upper part of the os sacrum; the forehead presented a bulging appearance, owing to the non-development of the frontal bone; all the anterior part, down to superciliary ridges, was wanting, and merely the lateral and temporal sides were present; the gap occasioned by the junction of the two halves increased as the finger traced it upwards, whence only the anterior inferior angle (about one inch) of the parietal bone on each side could be felt; the parietal bones made a slight attempt at approximation at their posterior superior angles, from which points the occipital bone was only developed at the sides, the same as the frontal. Owing to this state of affairs, nearly two-thirds of the brain is deprived of its bony covering. The child sucks well, but occasionally turns its eyes inwards. Nothing unusual occurred during the pregnancy of the mother, beyond a neighbour informing her, whilst out walking, that she thought her house was on fire, which report did not attract her notice particularly at the time. The child is now doing well, and thriving.

June, 1856.

\section{difthror}

OF THE PRACTICE OF

\section{MEDICINE AND SURGERY IN THx}

\section{HOSPITALS OF LONDON.}

Nulla est alia pro certo noscendi via, nisi quam plurimas et morborum tiscectionum historias, tam aliorum proprias, collectas habere et inter se comparare.-Morgagni. De Sed et Caus. Mrorb. 1ib. 14. Procmium.

\section{KING'S COLLEGE HOSPITAL}

SEVERE LACERATTON OT THE LEFT FOOT FROM THE MACHINERY OF A WINDMILL; GOOD EFFECTS OF CONSERVATIVE SURGERY.

(Under the care of Mr. Fengusson.)

THE following case is an interesting example of the good effects of conservative surgery, in which a large portion of the outer part of the left foot was literally ground up by entanglement in machinery, and the foot was preserved. In such in. stances as these the usual recourse was amputation, but at the present day such a proceeding is not thought of until other measures adopted for the preservation of as much of the foot as possible have failed. The soft structures here were very 